\title{
Severe weight loss in a hypothyroid patient as an acute presentation of autoimmune polyglandular syndrome type II
}

\author{
Elvira Silajdzija ${ }^{1,2} \cdot$ Sofie Bliddal ${ }^{1,2,3} \cdot$ Line Borgwardt $^{4} \cdot$ Maria Rossing ${ }^{4}$ Anne Jarløv ${ }^{2} \cdot$ Claus Henrik Nielsen $^{1,3}$. \\ Ulla Feldt-Rasmussen ${ }^{1,2}$ (])
}

Received: 10 September 2021 / Accepted: 14 December 2021 / Published online: 19 February 2022

(c) The Author(s) 2022

\begin{abstract}
Background Autoimmune disease, including autoimmune thyroid disease, with uncharacteristic symptoms can be due to additional severe disease. We report a life-threatening debut of autoimmune polyglandular syndrome type II (APS II) defined as Addison's disease combined with autoimmune diabetes and/or thyroid disease.

Patient findings A 33-year-old male with newly diagnosed hypothyroidism was referred to a tertiary center due to fatigue and 20-kg rapid weight loss. Malignancy was excluded. After a gastroscopy, he developed Addison's crisis; he was admitted to our hospital and stabilized. Final diagnoses included Hashimoto's thyroiditis, Addison's disease, vitiligo, and pernicious anemia. Whole genome sequencing found no genetic variants associated with component diseases. Human leukocyte antigen typing revealed DR3/DR4 and DQ8/DQ2 heterozygosity associated with APS II.

Summary A patient with Hashimoto's thyroiditis and weight loss presented with Addison's crisis and was diagnosed with APS II.

Conclusions Awareness of potential polyautoimmunity in clinical evaluation of patients with thyroid disease improves diagnosis and can be lifesaving.
\end{abstract}

Keywords Autoimmune polyglandular syndrome type II $\cdot$ HLA $\cdot$ Hypothyroidism $\cdot$ Autoimmunity $\cdot$ Addison's disease . Diabetes

\section{Introduction}

In 1926, Martin Benno Schmidt described the association of Addison's disease and chronic lymphatic thyroiditis and named it "Schmidt's syndrome." Now more commonly

Elvira Silajdzija and Sofie Bliddal are co-first authors

\author{
Ulla Feldt-Rasmussen \\ ufeldt@rh.dk \\ Elvira Silajdzija \\ elvirasilajdzija@gmail.com \\ Sofie Bliddal \\ sofiebliddal@gmail.com \\ Line Borgwardt \\ Line.Gutte.Borgwardt@regionh.dk \\ Maria Rossing \\ caroline.maria.rossing@ regionh.dk \\ Anne Jarløv \\ anne.elisabeth.jarloev@ regionh.dk
}

Claus Henrik Nielsen

Claus.Henrik.Nielsen@ regionh.dk

1 Faculty of Health and Medical Research, Copenhagen

University, Copenhagen, Denmark

2 Department of Medical Endocrinology and Metabolism, Rigshospitalet, Copenhagen University, Copenhagen, Denmark

3 Institute of Inflammation Research, Center for Rheumatology and Spine Diseases, Rigshospitalet, Copenhagen University, Copenhagen, Denmark

4 Center for Genomic Medicine, Rigshospitalet, Copenhagen University, Copenhagen, Denmark 
referred to as autoimmune polyglandular syndrome type II (APS II), the syndrome is defined by the presence of Addison's disease together with diabetes mellitus type I and/or autoimmune thyroid disease [1] and occurs in approximately 1 per 20,000 inhabitants [2]. The cause is likely multifactorial including a genetic predisposition $[1,2]$.

Uncharacteristic symptoms presenting in patients with an autoimmune disease can be a sign of additional underlying severe disease. We present a case of hypothyroidism and severe weight loss as a reminder that polyautoimmunity is potentially a life-threatening phenomenon.

\section{Patient}

A 33-year-old male consulted his general practitioner due to severe fatigue and an unintended weight loss of $20 \mathrm{~kg}$ over 3 months. Apart from suffering from vitiligo since childhood, the patient reported being in good health. He fathered two children without need of fertility treatment.

\section{Family history}

The patient's father had, like his son, suffered from vitiligo since childhood. The patient's mother died of liver cancer in her 60s. The patient had one half-sister on his mother's side. Both the mother and the half-sister had rheumatoid arthritis. There were no other known diseases (including thyroid disease, diabetes, and other endocrine diseases) among the relatives.

\section{Initial work-up}

The patient's general practitioner measured his thyroid function and diagnosed the patient with autoimmune hypothyroidism (positive thyroid peroxidase antibodies and thyroid stimulating hormone (TSH) of $44 \mathrm{mIU} / \mathrm{L}$ ). Due to his weight loss, the patient was referred to a tertiary referral center on suspicion of malignancy. The clinical examination found no signs of tumors or lymphadenopathy, chest X-ray was normal, and an abdominal ultrasound scan showed slight steatosis but was otherwise normal. The possibility of polyautoimmunity was explored by referral to the gastrointestinal unit and the endocrine unit. A gastroscopy revealed signs of autoimmune gastritis, which was later confirmed by histological examination of ventricular biopsies. The patient subsequently reported having been unable to get out of bed in the days following the gastroscopy as well as being extremely tired, nauseous, and unable to eat or drink.

\section{Endocrine unit}

Three days after the gastroscopy, the patient was brought to the tertiary endocrine out-patient clinic, where a Synacthen ${ }^{\circledR}$ test revealed a critically low 30-min p-cortisol of $33 \mathrm{nmol} / \mathrm{L}((1.2 \mu \mathrm{g} / \mathrm{dL})$, reference $\geq 420 \mathrm{nmol} / \mathrm{L}(15.22 \mu \mathrm{g} /$ $\mathrm{dL})$ ). He was immediately admitted as an in-patient and treated for Addison's crisis according to standard of care.

Physical examination showed poor general appearance, white patches on multiple areas of the skin, hyperpigmentation in the remaining skin areas (Fig. 1A and 1B), and slight activity-related dyspnea. The patient's blood pressure was

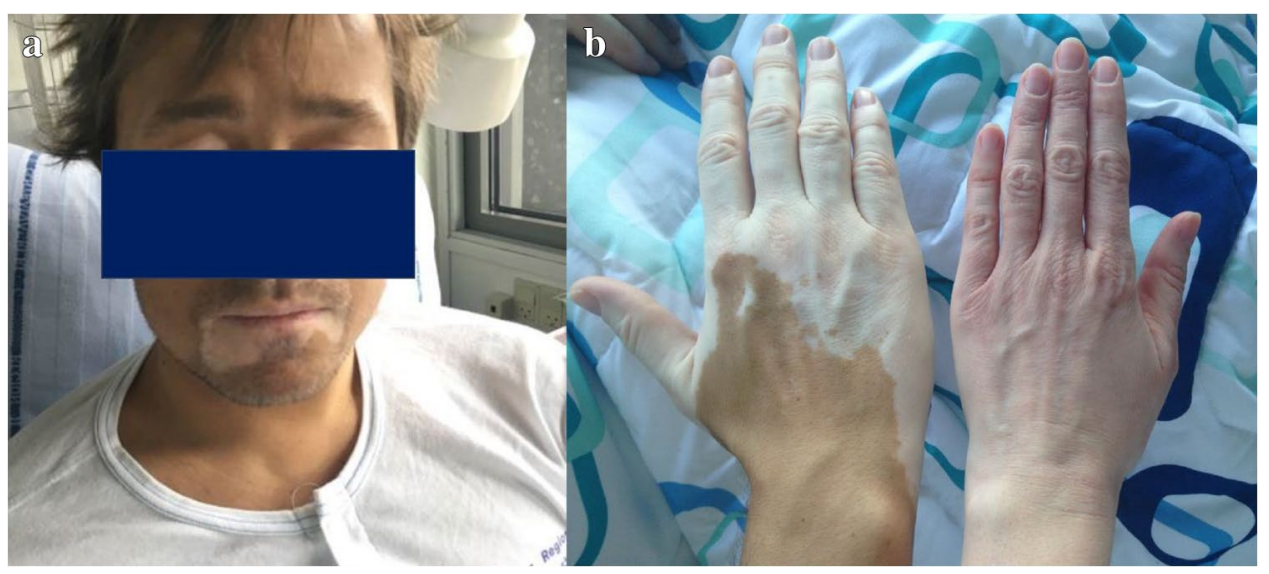

Fig. 1 A, B Hypopigmentation and hyperpigmentation in a patient with hypothyroidism. The patient had characteristic physical appearance with both hypopigmentation due to his vitiligo and hyperpigmentation due to excessive ACTH production preceded by the cleavage of the prohormone, pro-opiomelanocortin (POMC) leaving melanocyte-stimulating hormone as a by-product (A). This was especially visible when compared with a standard Caucasian Danish winter tan (right-hand picture, right hand) (B). Pictures published with permission from the patient 
74/69 mmHg upon admission. Acute administration of iv. hydrocortisone and isotonic saline enabled stabilization.

The patient was diagnosed with Addison's disease, Hashimoto's thyroiditis, vitiligo, and pernicious anemia (and high-level anti-glutamate decarboxylase 65 autoantibodies) consistent with APS II. His condition markedly improved following treatment with hydrocortisone, fludrocortisone, hydroxycobalamine, and levothyroxine substitution. Table 1 depicts results from blood tests upon admission to the endocrine unit and 1 year later.

\section{Follow-up}

Over 1 year of follow-up, the patient experienced increasing well-being and was able to resume his job within a couple of months from diagnosis.

\section{Genetic analyses}

The patient and his father went through whole genome sequencing (WGS) and a CytoScan HD array analysis to screen for potential pathogenic variants and copy number alterations, respectively. No pathogenic variants or copy number alterations associated with the phenotype were identified by genomic screening despite a thorough search including genetic components involved in immunoregulation (i.e., cytotoxic T-lymphocyte-associated antigen-4 (CTLA-4), protein tyrosine phosphatase, non-receptor type 22 (PTPN22), and signal transducer and activator of transcription 4 (STAT4)).

HLA typing was performed by next generation sequencing (NGS) and revealed the following HLA haplotypes:

Table 1 Laboratory tests at time of admission and at 1-year follow-up

\begin{tabular}{lll}
\hline Test & At admission & $\begin{array}{l}\text { At 1-year } \\
\text { follow-up }\end{array}$ \\
\hline P-sodium (137-144 mmol/L) & 124 & 142 \\
ACTH $(2-11 \mathrm{pmol} / \mathrm{L})$ & 280 & 12 \\
TSH $(0.4-4.8 \mathrm{mIU} / \mathrm{L})$ & 62 & 6.39 \\
Total T4 $(70-140 \mathrm{nmol} / \mathrm{L})$ & 68 & 85 \\
Free T4 $(12-22 \mathrm{pmol} / \mathrm{L})$ & 8.2 & 17.1 \\
Hemoglobin $(8.3-10.5 \mathrm{mmol} / \mathrm{L})$ & 7.1 & $\mathrm{NA}$ \\
Vitamin B12 $(>200 \mathrm{pmol} / \mathrm{L})$ & 98 & 303 \\
HbA1c $(<48 \mathrm{mmol} / \mathrm{mol})$ & 35 & 34 \\
\hline
\end{tabular}

Standard blood work-up at time of admission and at 1-year follow-up. Further tests showed high concentrations of antibodies towards thyroid peroxidase, the cortical adrenal gland, gastric parietal cells, and glutamate decarboxylase 65 . Reference intervals appear in the parentheses

Abbreviations: ACTH, adrenocorticotropic hormone; HbAlc, hemoglobin A1c; $N A$, not available; $T 4$, thyroxine; $T S H$, thyroid stimulating hormone
HLA-A*03:01-B*07:02-C*07:02-DRB 1*04:01:01GDQB $1 * 03: 02-\mathrm{DPB} 1 * 02: 01$ and HLA-A $* 01: 01$-HLAB*08:01-C*07:01-DRB 1*03:01:01G-DQB 1*02:01DPB 1*04:01.

\section{Discussion}

APS II is a rare, but potentially life-threatening disease, as seen in the presented case. In general, there is an increased risk of development of other autoimmune disorders in patients with autoimmune endocrinopathies, of which thyroid disease is the most common [3-5]. Clinical awareness of this fact can save lives, specifically, by performing a corticotropin stimulation test for Addison's disease prior to other examinations and treatments, in order to minimize the risk of Addison's crisis. Furthermore, the various phenotypic presentations of the diseases of the syndrome will define the clinical challenges in individual patients. Accordingly, for example, pernicious anemia can reduce the uptake of any oral treatment, thus necessitating increasing the treatment dose. This is often the case in patients treated with levothyroxine due to hypothyroidism. Autoimmune thyroid disease is the most common autoimmune disease, and is often an overlooked disease co-occurring with other autoimmune diseases (particularly in males) [6]. Other autoimmune diseases compromising gastrointestinal absorption include ulcerative colitis, celiac disease [7, 8], and systemic lupus erythematosus [9]. Failure to recognize autoimmune hypothyroidism or Addison's disease can further result in severe hypoglycemia in type 1 diabetes mellitus.

The highly polymorphic human leukocyte antigen (HLA) molecules determine the recognition pattern of cytotoxic $\mathrm{T}$ cells, $\mathrm{T}$-helper cells, and regulatory $\mathrm{T}$ cells. Specific genetic variants of the HLA region located on chromosome 6 have been associated with most autoimmune diseases as a risk factor for the loss of self-tolerance. Among the first studies of HLA types in APS II patients, haplotypes including HLA-A1 or HLA-B8 were shown to be more prevalent among patients than relatives without disease or healthy controls [10-13]. Later, the specification of HLA-DR3-DQ2 or DR4-DQ8 (serotype DQ2 corresponding to genotype (DQA $1 * 0501)$-DQB $1 * 0201$ and DQ8 to (DQA $1 * 0301)$-DQB $1 * 0302$ ) was convincingly demonstrated in several studies [14-17]. Myhre et al. [14] found the DR3-DQ2/DR4-DQ8 genotype in 29 of $74(39.2 \%)$ of patients with Addison's disease compared to 5 of $290(1.7 \%)$ healthy controls (odds ratio 36.7, $p$-value $<0.001$ ), and this was especially prevalent among APS II patients (10 of 12 patients had this haplotype). Huang et al. [18] also demonstrated the synergistic effect of the presence of this heterozygosity (DRB $1 * 03$ DQB1*0201/ DRB1*04-DQB1*0302) in seven of 17 
Table 2 Serological testing for autoantibodies in patients with suspected polyglandular autoimmune syndrome type II

\begin{tabular}{ll}
\hline Autoantibodies against & Component disease \\
\hline TPO & Hashimoto's thyroiditis \\
GAD-65, IA-2, ZnT8 & Type 1 diabetes \\
21-hydroxylase & Addison's disease \\
Ovaries*, side-chain & Premature ovarian insufficiency \\
cleavage enzyme, & \\
21-hydroxylase & \\
Intrinsic factor, & Autoimmune gastritis, pernicious anemia \\
$\mathrm{H}^{+} \mathrm{K}^{+}$ATPase, parietal & \\
cell & \\
Transglutaminase-2 & Celiac disease \\
\hline
\end{tabular}

Overview of autoantibodies found in component diseases of polyglandular autoimmune syndrome type II. Adapted from Husebye et al. [26]

*Anti-ovarian antibodies consist of a sum of antibodies against ovarian tissue antigens and may differ between commercial assays

Abbreviations: $G A D-65$, glutamic acid decarboxylase-65; $I A-2$, islet antibody-2; TPO, thyroid peroxidase; $Z n T 8$, zinc transporter 8

(41\%) APS II patients compared to five of 191 (3\%) healthy controls (odds ratio 26, $p<0.001$ ). Most recently, Frommer et al. [19] confirmed that APS II (and other subgroups of APS) differed significantly from controls in DQA1, DQB1, and DRB 1 alleles $(p<0.0001)$. This included particularly haplotypes DRB 1*03:01-DQA1*05:01-DQB 1*02:01 and DRB 1*04:01-DQA1*03:01-DQB1*03:02 (approx. $50 \%$ in APS II vs. $15 \%$ in controls [specific proportions not given]). Some of these studies suggested differences between various subtypes of APS II depending on the component diseases $[18,19]$. HLA-DR3-DQ2/DR4-DQ8 has also been strongly associated with type 1 diabetes mellitus and celiac disease [20,21]. A study of the general Danish population found $4.1 \%$ to be heterozygous for HLA-DQ2-DQ8 [22]. Overall, these findings match the haplotype of the patient in the present case report.

Although not so in the present case, several other genetic components involved in immunoregulation (i.e., CTLA-4, PTPN22, and STAT4) have also been associated with the different components of APS II [1, 23-26]. Recent advances in genetic testing, e.g., WGS, will likely expand our knowledge of possible genetic risk factors in APS II [27-29] and help describe the multivariant genetic character of the disease including differences between various subtypes. New genetic landmarks may thus offer a more personalized approach to patient care compared to what is currently possible by using only serological monitoring (Table 2).

\section{Conclusion}

As a reminder of a potentially life-threatening phenomenon, we report a case of polyautoimmunity presenting as hypothyroidism and severe weight loss developing into an Addison's crisis. The patient was diagnosed with Hashimoto's thyroiditis, Addison's disease, vitiligo, and pernicious anemia (and high-level anti-glutamate decarboxylase 65 autoantibodies) consistent with APS II. Genetic testing demonstrated heterozygosity of HLA-DR3-DQ2 and DR4DQ8, which have previously been associated with APS II.

Awareness of the possibility of polyautoimmunity in patients with autoimmune thyroid disease is important for establishing a clinical diagnosis and can be lifesaving, as seen in the present patient report.

Acknowledgements The patient gave written and oral consent to this case report. We owe great thanks to the patient and his family for allowing us to share clinical and diagnostic information

Author contribution AJ was in charge of the patient's clinical examinations during admission and follow-up. SB and UFR were in contact with the patient regarding this case report and genetic testing. LB and MR performed the genetic analyses and interpretations thereof. ES and SB contributed equally to the writing of the manuscript. All authors critically reviewed, discussed, and approved the manuscript.

Funding Ulla Feldt-Rasmussen's research salary is supported by a grant from Kirsten and Freddy Johansen's Foundation. Sofie Bliddal is supported by grants from the Copenhagen University Hospital (Rigshospitalet), Musikforlæggerne Agnes and Knut Mørk's Foundation, Desiree and Niels Yde's Foundation, the Danish Medical Association's Research Foundation, the A.P. Møller Foundation for the Advancement of Medical Science, and the Danish Thyroid Patient Association. The foundations had no influence on the examinations or the writing of this manuscript.

\section{Declarations}

Conflict of interest The authors declare no competing interests.

Open Access This article is licensed under a Creative Commons Attribution 4.0 International License, which permits use, sharing, adaptation, distribution and reproduction in any medium or format, as long as you give appropriate credit to the original author(s) and the source, provide a link to the Creative Commons licence, and indicate if changes were made. The images or other third party material in this article are included in the article's Creative Commons licence, unless indicated otherwise in a credit line to the material. If material is not included in the article's Creative Commons licence and your intended use is not permitted by statutory regulation or exceeds the permitted use, you will need to obtain permission directly from the copyright holder. To view a copy of this licence, visit http://creativecommons.org/licenses/by/4.0/. 


\section{References}

1. Michels AW, Gottlieb PA (2010) Autoimmune polyglandular syndromes. Nat Rev Endocrinol 6:270-277

2. Kahaly GJ, Frommer L (2019) Autoimmune polyglandular diseases. Best Pract Res Clin Endocrinol Metab 33:101344

3. Boelaert K, Newby PR, Simmonds MJ, Holder RL, Carr-Smith JD, Heward JM, Manji N, Allahabadia A, Armitage M, Chatterjee KV, Lazarus JH, Pearce SH, Vaidya B, Gough SC, Franklyn JA (2010) Prevalence and relative risk of other autoimmune diseases in subjects with autoimmune thyroid disease. Am J Med 123:183-189

4. Bliddal S, Nielsen CH, Feldt-Rasmussen U 2017 Recent advances in understanding autoimmune thyroid disease: the tallest tree in the forest of polyautoimmunity. F1000Res 6:1776.

5. Eaton WW, Rose NR, Kalaydjian A, Pedersen MG, Mortensen PB (2007) Epidemiology of autoimmune diseases in Denmark. J Autoimmun 29:1-9

6. Ottesen M, Feldt-Rasmussen U, Andersen J, Hippe E, Schouboe A (1995) Thyroid function and autoimmunity in pernicious anemia before and during cyanocobalamin treatment. J Endocrinol Invest 18:91-97

7. d'Esteve-Bonetti L, Bennet AP, Malet D, Hoff M, Louvet JP, Caron P (2002) Gluten-induced enteropathy (coeliac disease) revealed by resistance to treatment with levothyroxine and alfacalcidol in a sixty-eight-year-old patient: a case report. Thyroid 12:633-636

8. Rayman MP (2019) Multiple nutritional factors and thyroid disease, with particular reference to autoimmune thyroid disease. Proc Nutr Soc 78:34-44

9. Lobasso A, Nappi L, Barbieri L, Peirce C, Ippolito S, Arpaia D, Rossi FW, de PA, Biondi B, (2017) Severe hypothyroidism due to the loss of therapeutic efficacy of l-thyroxine in a patient with esophageal complication associated with systemic sclerosis. Front Endocrinol (Lausanne) 8:241

10. Eisenbarth GS, Wilson PW, Ward F, Buckley C, Lebovita H (1979) The polyglandular failure syndrome: disease inheritance, HLA type, and immune function. Ann Intern Med 91:528-533

11. Eisenbarth GS, Lebovitz HE (1978) Immunogenetics of the polyglandular failure syndrome. Life Sci 22:1675-1683

12. Neufeld M, Maclaren NK, Blizzard RM (1981) Two types of autoimmune Addison's disease associated with different polyglandular autoimmune (PGA) syndromes. Medicine (Baltimore) 60:355-362

13. Maclaren NK, Riley WJ (1986) Inherited susceptibility to autoimmune Addison's disease is linked to human leukocyte antigensDR3 and/or DR4, except when associated with type I autoimmune polyglandular syndrome. J Clin Endocrinol Metab 62:455-459

14. Myhre AG, Undlien DE, Lovas K, Uhlving S, Nedrebo BG, Fougner KJ, Trovik T, Sorheim JI, Husebye ES (2002) Autoimmune adrenocortical failure in Norway autoantibodies and human leukocyte antigen class II associations related to clinical features. J Clin Endocrinol Metab 87:618-623

15. Flesch BK, Matheis N, Alt T, Weinstock C, Bux J, Kahaly GJ (2014) HLA class II haplotypes differentiate between the adult autoimmune polyglandular syndrome types II and III. J Clin Endocrinol Metab 99:E177-E182

16. Erichsen MM, Lovas K, Skinningsrud B, Wolff AB, Undlien DE, Svartberg J, Fougner KJ, Berg TJ, Bollerslev J, Mella B, Carlson JA, Erlich H, Husebye ES (2009) Clinical, immunological, and genetic features of autoimmune primary adrenal insufficiency: observations from a Norwegian registry. J Clin Endocrinol Metab 94:4882-4890

17. Larina AA, Troshina EA, Ivanova ON (2018) The association between the development of autoimmune polyglandular syndrome in adults and polymorphism of HLA class II genes and the predisposition to the development of chronic adrenal insufficiency in the context of these syndromes. Ter Arkh 90:23-29

18. Huang W, Connor E, Rosa TD, Muir A, Schatz D, Silverstein J, Crockett S, She JX, Maclaren NK (1996) Although DR3DQB $1 * 0201$ may be associated with multiple component diseases of the autoimmune polyglandular syndromes, the human leukocyte antigen DR4-DQB $1 * 0302$ haplotype is implicated only in beta-cell autoimmunity. J Clin Endocrinol Metab 81:2559-2563

19. Frommer L, Flesch BK, Konig J, Kahaly GJ 2020 Amino acid polymorphisms in Hla class II differentiate between thyroid and polyglandular autoimmunity. J Clin Endocrinol Metab 105: dgz164.

20. Smigoc SD, Mendez A, Kunilo JS, Bratanic N, Bratina N, Battelino T, Brecelj J, Vidan-Jeras B (2016) High-risk genotypes HLA-DR3-DQ2/DR3-DQ2 and DR3-DQ2/DR4-DQ8 in cooccurrence of type 1 diabetes and celiac disease. Autoimmunity 49:240-247

21. Lund F, Hermansen MN, Pedersen MF, Hillig T, Toft-Hansen H, Soletormos G (2015) Mapping of HLA- DQ haplotypes in a group of Danish patients with celiac disease. Scand J Clin Lab Invest 75:519-522

22. Karhus LL, Thuesen BH, Skaaby T, Rumessen JJ, Linneberg A (2018) The distribution of HLA DQ2 and DQ8 haplotypes and their association with health indicators in a general Danish population. United European Gastroenterol J 6:866-878

23. Ueda H, Howson JM, Esposito L, Heward J, Snook H, Chamberlain G, Rainbow DB, Hunter KM, Smith AN, Di GG, Herr MH, Dahlman I, Payne F, Smyth D, Lowe C, Twells RC, Howlett S, Healy B, Nutland S, Rance HE, Everett V, Smink LJ, Lam AC, Cordell HJ, Walker NM, Bordin C, Hulme J, Motzo C, Cucca F, Hess JF, Metzker ML, Rogers J, Gregory S, Allahabadia A, Nithiyananthan R, Tuomilehto-Wolf E, Tuomilehto J, Bingley P, Gillespie KM, Undlien DE, Ronningen KS, Guja C, Ionescu-Tirgoviste C, Savage DA, Maxwell AP, Carson DJ, Patterson CC, Franklyn JA, Clayton DG, Peterson LB, Wicker LS, Todd JA, Gough SC (2003) Association of the T-cell regulatory gene CTLA4 with susceptibility to autoimmune disease. Nature 423:506-511

24. Mitchell AL, Macarthur KD, Gan EH, Baggott LE, Wolff AS, Skinningsrud B, Platt H, Short A, Lobell A, Kampe O, Bensing S, Betterle C, Kasperlik-Zaluska A, Zurawek M, Fichna M, Kockum I, Nordling EG, Ekwall O, Wahlberg J, Dahlqvist P, Hulting AL, Penna-Martinez M, Meyer G, Kahles H, Badenhoop K, Hahner S, Quinkler M, Falorni A, Phipps-Green A, Merriman TR, Ollier W, Cordell HJ, Undlien D, Czarnocka B, Husebye E, Pearce SH (2014) Association of autoimmune Addison's disease with alleles of STAT4 and GATA3 in European cohorts. PLoS One 9:e88991

25. Roycroft M, Fichna M, McDonald D, Owen K, Zurawek M, Gryczynska M, Januszkiewicz-Lewandowska D, Fichna P, Cordell H, Donaldson P, Nowak J, Pearce S (2009) The tryptophan 620 allele of the lymphoid tyrosine phosphatase (PTPN22) gene predisposes to autoimmune Addison's disease. Clin Endocrinol (Oxf) 70:358-362

26. Husebye ES, Anderson MS, Kampe O (2018) Autoimmune polyendocrine syndromes. N Engl J Med 378:1132-1141 
27. Visscher PM, Wray NR, Zhang Q, Sklar P, McCarthy MI, Brown MA, Yang J (2017) 10 years of GWAS discovery: biology, function, and translation. Am J Hum Genet 101:5-22

28. Rotival M (2019) Characterising the genetic basis of immune response variation to identify causal mechanisms underlying disease susceptibility. HLA 94:275-284
29. Guo X, Rotter JI (2019) Genome-wide association studies. JAMA 322:1705-1706

Publisher's note Springer Nature remains neutral with regard to jurisdictional claims in published maps and institutional affiliations. 